ARTIGO

\title{
Avaliação das aprendizagens nas aulas de ciências naturais e biologia e geologia: das perceções às práticas
}

\author{
Sónia de Jesus Elias Correia' (D) \\ Marília Pisco Castro Cid' (D
}

\section{RESUMO}

A avaliação das (e para as) aprendizagens tem vindo a assumir uma presença cada vez maior no campo da investigação em Educação. Uma das premissas incontornáveis assume que, ao contrário do que ainda se continua a verificar, a avaliação não deve ser entendida como extrínseca ao processo de ensino e de aprendizagem, pois encontra-se intimamente ligada aos componentes que envolvem o ato de ensinar e de aprender. $\mathrm{O}$ artigo resulta de estudo de caso realizado numa escola portuguesa, que pretendeu caracterizar estratégias de avaliação e conhecer perceções sobre avaliação das aprendizagens nas disciplinas de Ciências Naturais e Biologia e Geologia. O estudo seguiu uma abordagem qualitativa, de natureza interpretativa. As práticas de avaliação observadas estão associadas às perceções que professor e alunos manifestam sobre avaliação e mostram-se mais orientadas para a classificação e seleção dos alunos do que para a melhoria dos processos de ensino e de aprendizagem.

\section{PALAVRAS-CHAVE}

avaliação das aprendizagens; avaliação para as aprendizagens; práticas avaliativas; perceções.

'Universidade de Évora, Évora, Portugal. 


\title{
EVALUATION OF LEARNING IN NATURAL SCIENCE AND BIOLOGY AND GEOLOGY CLASSES: FROM PERCEPTIONS TO PRACTICES
}

\begin{abstract}
The evaluation of (and for) the learning has been assuming an increasing presence in the field of the investigation in the Education. One of the unavoidable premises assumes that, contrary to what is still to be verified, the evaluation should not be understood as extrinsic to the teaching and learning process, as it is closely linked to the components that involve the act of teaching and learning. The article is the result of a case study carried out in a Portuguese school, which aimed to characterize assessment strategies and to know perceptions about learning assessment in the disciplines of Natural Sciences and Biology and Geology. The study followed a qualitative approach of an interpretative nature. The assessment practices observed are associated with the perceptions that teachers and students express about assessment, they are more oriented to the classification and selection of students than to the improvement of the teaching and learning processes.
\end{abstract}

\section{KEYWORDS}

evaluation of learning; evaluation for learning; evaluation practices; perceptions.

\section{EVALUACIÓN DEL APRENDIZAJE EN CIENCIAS NATURALES Y CLASES DE BIOLOGÍA Y GEOLOGÍA: DE LAS PERCEPCIONES A LAS PRÁCTICAS}

\section{RESUMEN}

La evaluación de (y para) el aprendizaje ha estado asumiendo una presencia creciente en el campo de la investigación en la Educación. Una de las premisas inevitables supone que, al contrario de lo que aún no se ha verificado, la evaluación no debe entenderse como extrínseca al proceso de enseñanza y aprendizaje, ya que está estrechamente vinculada a los componentes que implican el acto de enseñar y aprender. El artículo es el resultado de un estudio de caso realizado en una escuela portuguesa, cuyo objetivo era caracterizar estrategias de evaluación y conocer las percepciones sobre la evaluación del aprendizaje en las disciplinas de Ciencias Naturales y Biología y Geología. El estudio siguió un enfoque cualitativo de naturaleza interpretativa. Las prácticas de evaluación observadas están asociadas con las percepciones que los profesores y los alumnos expresan sobre la evaluación, están más orientadas a la clasificación y selección de alumnos que a la mejora de los procesos de enseñanza y aprendizaje.

\section{PALABRAS CLAVE}

evaluación de los aprendizajes; evaluación para los aprendizajes; prácticas evaluativas; percepciones. 


\section{INTRODUÇÃO}

A avaliação não deve ser entendida como extrínseca ao processo de ensino e de aprendizagem, pois encontra-se intimamente ligada aos componentes que envolvem o ato de ensinar e de aprender, tendo, assim, papel específico em relação ao conjunto de componentes que integram o ensino como um todo (Fernandes, 2005). Autores como Paul Black, Dylan Wiliam, Wynne Harlen e John Gardner defendem que a avaliação é considerada parte integrante do processo de ensino e de aprendizagem (Cid e Fialho, 2013) e, para além disso, é de acrescentar que essa aceção só pode ser considerada se a avaliação praticada se basear em processos que garantam a melhoria das aprendizagens: falamos, pois, de uma avaliação formadora e reguladora dos processos de ensino e de aprendizagem (Black e Wiliam, 1998a, 1998b; Cid e Fialho, 2013) que possibilite ao aluno o desenvolvimento de competências de autorregulação dos processos de aprendizagem por meio do feedback, da autoavaliação e da avaliação por pares, ajudando o aluno a "aprender a aprender".

Nessa modalidade de avaliação, os alunos são o principal agente no desenvolvimento da aprendizagem por intermédio da autorregulação, que potencia a regulação e a melhoria das aprendizagens por meio do feedback fornecido nas diferentes tarefas (Black e Wiliam, 2006b; Fernandes, 2006).

No entanto, por muito conhecidos que sejam os benefícios da avaliação formativa (formadora e reguladora), os professores parecem continuar a privilegiar práticas de avaliação sumativa por serem, no seu entender, mais fáceis de utilizar. Desse modo, o equilíbrio entre avaliação formativa e sumativa surge como dificuldade, evidenciada em vários estudos que mostram que a avaliação formativa (formadora e reguladora) é ainda pouco frequente e é mais baseada na intuição do professor do que na recolha deliberada e propositada de informação (Fernandes, 2008a, 2008b, 2009a, 2009b).

A avaliação formadora e reguladora deverá, então, estar integrada na planificação, preocupar-se com a forma como os alunos aprendem e ser prática central em sala de aula, correspondendo a uma competência profissional essencial ao professor. Essa modalidade de avaliação é, assim, sensível e construtiva, motivadora, facilita a compreensão de objetivos e critérios, ajuda os alunos a saber como melhorar, desenvolve a capacidade de autoavaliação, reconhece todas as aprendizagens, centra-se nos alunos mas também nos professores, implica a ligação entre o ensino e a aprendizagem e afasta-se de uma abordagem de ensino centrada na transmissão (Wiliam, 2009; Cid e Fialho, 2013). Além disso, possibilita ao aluno a tomada de consciência da sua evolução em termos de aprendizagem por meio da sua autoavaliação, permitindo que nele intervenha de forma autónoma, de modo a superar dificuldades e erros ou a continuar a aprendizagem com sucesso. Para o professor, essa modalidade de avaliação será também formadora porque permite refletir sobre a adequação das estratégias de ensino aos percursos de aprendizagem dos diferentes alunos, modificando-as ou procurando novas estratégias de se evidenciarem dificuldades/ erros e diferentes ritmos de aprendizagem dos alunos (Ferreira, 2010). Os estudos efetuados por Black e Wiliam (1998a, 1998b) corroboravam já as aceçôes explanadas, destacando-se as seguintes conclusões: 
- a avaliação formativa duplica a velocidade de aprendizagem dos alunos;

- a sua prática sistemática melhora substancialmente a aprendizagem;

- os alunos que revelam mais dificuldades de aprendizagem são os que mais se beneficiam de tais práticas;

- os alunos que frequentam aulas em que a avaliação predominante é de natureza formativa obtêm melhores resultados em exames e provas de avaliação externa do que os alunos que frequentam aulas em que a avaliação é essencialmente sumativa (Black e Wiliam, 1998a, 1998b; Borralho, Fialho e Cid, 2015).

Nesse contexto, professores, alunos epares podem assumir diferentes papéis e utilizar diversas estratégias de avaliação formativa (Black e Wiliam, 1998a, 1998b; Borralho, Fialho e Cid, 2015). Logo, as práticas de avaliação devem contar com a participação ativa de todos os alunos e contribuir para a melhoria das suas aprendizagens (Fernandes, 2009a, 2009b).

Com base nesses pressupostos, procurou-se compreender, por meio da observação direta em sala de aula, a relação que se estabelece entre as avaliações formativa e sumativa, tendo em consideração tanto a perspetiva do professor envolvido no estudo como o grau de envolvimento dos alunos no processo de ensino, avaliação e aprendizagem.

Nessa sequência de ideias, surgiu a preocupação em estudar duas salas de aula, de dois anos de escolaridade distintos, $7 .^{\circ}$ ano do ensino básico, na disciplina de Ciências Naturais, e $11 .^{\circ}$ ano do ensino secundário, na disciplina de Biologia e Geologia, com vista ao conhecimento de uma situação concreta. Pretendeu-se conhecer as práticas de avaliação implementadas pelo professor em duas salas de aula de anos de escolaridade diferenciados, bem como as perceções do professor e dos alunos no que respeita à avaliação das aprendizagens.

\section{A AVALIAÇÃO FORMATIVA, VÁRIAS PERSPETIVAS PARA UM MESMO PROPÓSITO}

Quando se fala em avaliação formativa é necessário ter em conta que esse conceito evoluiu ao longo dos anos e nem sempre correspondeu à ideia de uma avaliação formadora e reguladora das aprendizagens, tal como referem Fernandes (2006), James (2006) e Shepard (2000, 2001).

A partir dos anos noventa do século passado, diversos autores, divergindo num ou noutro aspeto pontual, atribuíram outras designações à avaliação formativa: avaliação formadora, de Nunziati (1990) e Abrecht (1991); avaliação reguladora, de Allal (1986) e Perrenoud (1999); regulação controlada pelos processos de aprendizagem, de Perrenoud (1999); avaliação alternativa, de Berlak (1992a, 1992b), Gipps e Stobart (2003); avaliação formativa alternativa, de Fernandes (2006), a avaliação para a aprendizagem, de Black et al. (2011) e a avaliação reguladora, de Pinto e Santos (2006a, 2006b) e de Santos (2011). 
Apesar de os termos apresentados serem diferentes e terem características diferenciadas, todos eles se referem a uma avaliação baseada na melhoria das aprendizagens, ultrapassando as aceções behavioristas da avaliação (limitada à verificação e à consecução de objetivos comportamentais). No entanto, como já referimos, não se encontra ainda generalizada uma avaliação formativa com regulação interativa das aprendizagens, em que as dificuldades dos alunos possam ser detetadas regularmente durante, e não após, o processo de ensino e de aprendizagem, assim como verificaram Black e Wiliam (1998a, 1998b), Dwyer (1998), Fernandes (2006), Harlen (2006) e Harlen e James (1997) nos seus estudos relativamente às práticas de avaliação formativa implementadas em sala de aula.

Os autores francófonos tendem a considerar a avaliação formativa como um processo regulador da aprendizagem (Andrade, 2013; Bonniol e Vial, 2001; Cardinet, 1991; Grégoire, 1996; Perrenoud, 1999) e ver os processos cognitivos e metacognitivos como sendo internos ao aluno (o autocontrolo, a autoavaliação ou a autorregulação). O mais importante é focalizar a atenção na forma como os alunos aprendem, para que se possa pôr em prática uma avaliação formativa que ajude os alunos a autorregular a aprendizagem. Não menosprezando a importância do feedback, esses autores referem que esse dispositivo, por si só, não garante a adequada regulação dos processos de aprendizagem, uma vez que é influenciado por fatores como a natureza das tarefas e pelos processos de regulação utilizados pelos alunos e professores (Fernandes, 2006; 2008b). Para Perrenoud (1999) e Fernandes (2006, 2007), a avaliação formativa é um processo de autoavaliação, em que os alunos têm papel central e autónomo, cabendo ao professor a tarefa de promover uma regulação interativa que implique a participação e o envolvimento dos alunos de forma responsável nos processos de autoavaliação e autorregulação das suas aprendizagens. Parte-se do princípio de que se os alunos utilizarem adequadamente a autoavaliação, serão capazes de regular as suas aprendizagens, podendo o recurso aos professores ser, neste caso, pontual (Fernandes, 2008b).

$\mathrm{Na}$ tradição anglo-saxónica, defendida por autores como Black e Wiliam (1998a, 1998b, 2006a, 2006b), Gardner (2006), Gipps (1994) e Stiggins e Conklin (1992), a avaliação formativa está mais relacionada com o apoio ou a orientação que os professores podem prestar aos alunos na concretização de tarefas e no desenvolvimento de aprendizagens previstas no currículo (Fernandes, 2006, 2008b). Os autores anglo-saxónicos consideram o feedback a peça fundamental da avaliação formativa (Black e Wiliam, 1998a, 1998b, 2006; Gipps, 1994, 1999; Gipps e Stobart, 2003; Shepard, 2001; Stiggins, 2004), sendo esse tipo de avaliação considerado um processo para melhorar as aprendizagens dos alunos, embora tenha de ser orientado pelos professores. Essa orientação ou apoio é importante para o processo de ensino e de aprendizagem (Fernandes, 2006, 2008b). A autoavaliação, apesar de ser um processo interno, está associada ao feedback que o docente atribui ao aluno e à tarefa, por isso depende da intervenção do professor (Fernandes, 2006).

O feedback associado à autoavaliação é o principal fator da avaliação formadora e reguladora, uma vez que é a partir da sua aplicação que os alunos tomam consciência do ponto onde se encontram, relativamente às suas aprendizagens. 
Nesse caso, recebem dos professores as orientações necessárias para ultrapassar as dificuldades (Sadler, 1989).

As perspetivas anglo-saxónicas sobre avaliação formativa destacam preocupação com a regulação dos processos de interação pedagógica e a respetiva comunicação entre intervenientes (Black, 2013; Gipps, 1999; Shepard, 2000). A sua realização depende da interação que se estabelece entre professor-aluno e aluno-professor, e destes com o saber (Black, 2013; Trindade e Cosme, 2010).

Quando se fala em avaliação formadora, fala-se da compreensão dos processos mentais dos alunos relativamente à aprendizagem, em que o erro assume aqui papel fundamental, pois permite compreender como pensa o aluno e as relações que se estabelecem num dado momento, passando, dessa forma, a ser visto como fonte poderosa de informação, quer para o professor quer para o aluno. No entanto, para que o acto de avaliação formadora aconteça, a recolha de informação deve sofrer interpretação da qual decorrerá ação reguladora, que poderá incidir sobre vários objetos:

- a clarificação entre os objetivos de aprendizagem e as tarefas a utilizar;

- a explicitação e a negociação dos critérios de avaliação (de realização e de sucesso), assim como a sua apropriação por parte dos alunos;

- a interpretação e a tomada de consciência dos erros cometidos na realização de uma tarefa (Santos, 2008).

Os processos de regulação, como a autoavaliação, permitem que os alunos tomem consciência das suas dificuldades e atuem autonomamente nos seus percursos de aprendizagem, com vista à superação de dificuldades e erros que possam surgir. Pretende-se, também, que o professor possa refletir sobre a adequação das tarefas e das estratégias de ensino implementadas, de acordo com as necessidades de cada aluno, reformulando-as sempre que necessário (París, 2006). As estratégias devem respeitar a diversidade social e cultural dos alunos, de acordo com as suas necessidades, de maneira que a avaliação formativa possa ter função reguladora no processo de ensino e de aprendizagem de cada aluno (Perrenoud, 1999).

Essa modalidade de avaliação não tem caráter classificativo nem seletivo. Não mede o sucesso nem o insucesso, na medida em que a informação obtida serve de retorno descritivo e pormenorizado para que alunos e professor percebam a origem das dificuldades (Crahay, 2007). A informação recolhida é avaliada em função dos critérios de realização das tarefas, os erros são encarados como fazendo parte da aprendizagem e, por isso, são objeto de análise para que os alunos possam compreender o que esteve na base da sua origem (Fernandes, 2006).

Relativamente às tarefas a concretizar, os critérios devem ser devidamente esclarecidos junto dos alunos ou até negociados, a fim de traçar o percurso, autocontrolando o processo de realização dessas tarefas, em função dos critérios delineados (Pacheco, 2002). Nesse processo, é importante que os alunos percecionem a que distância se encontram do cumprimento dos critérios de avaliação das tarefas, o que lhes vai permitir reformular o modo de realização destas e, no seu final, verificar o grau de cumprimento dos critérios que serviram de base para uma autoavaliação regulada (Allal, 1999). Cabe ao professor recolher e interpretar a informação de 
que necessita sobre a aprendizagem dos alunos, de forma continuada, por meio de diferentes instrumentos e técnicas de avaliação, como, por exemplo, a observação direta efetuada durante a realização das tarefas de aprendizagem, com grelhas de observação para o efeito, com listas de verificação e com o questionamento relativamente às estratégias e aos raciocínios efetuados durante a tarefa (Ferreira, 2007). Isso vai permitir ao professor diagnosticar as dificuldades e os erros durante a realização das tarefas e perceber o raciocínio dos alunos, atuando atempadamente no processo de ensino e de aprendizagem (Ferreira, 2007). Nesse processo, o mecanismo de retroação, ou feedback fornecido, é muito importante, pois permite aos alunos ganhar consciência daquilo que precisam melhorar, fazendo com que a qualidade do feedback atribuído pelo professor bem como a sua natureza, distribuição e frequência sejam a chave do progresso do processo de ensino e de aprendizagem (Fernandes, 2007). Ao permitir que os alunos retifiquem o seu processo de aprendizagem e que os professores ajustem o ensino às necessidades dos alunos, a avaliação formativa concretiza a sua função diagnóstica e reguladora. Essa modalidade de avaliação deve promover a responsabilidade dos alunos nos seus processos de aprendizagem (Fernandes, 2006).

A regulação das aprendizagens envolve, em suma, quatro processos principais:

- o estabelecimento de metas ou objetivos;

- o acompanhamento dos progressos em direção às metas e aos objetivos;

- a interpretação do feedback resultante da monitorização;

- o ajuste da ação de acordo com a meta ou objetivo ou a redefinição da própria meta ou objetivo (Allal, 2007, 2010; Andrade, 2013).

A regulação das aprendizagens pode ser definida em três modalidades, segundo Allal (1986): regulação proactiva, quando é efetuada antes do início de uma tarefa; regulação interativa, quando é realizada durante o processo que leva à consecução da tarefa; e regulação retroactiva, quando acontece no final de um conjunto de situações de aprendizagem. A investigação indica que a regulação interativa parece ser aquela que mais beneficia o aluno, por ser efetuada durante o processo de ensino e de aprendizagem e atuar atempadamente sobre o processo de aprendizagem (Santos, 2002). A comunicação estabelecida entre os intervenientes no processo de avaliação, por meio do feedback, é a chave central dessa modalidade de regulação, uma vez que ativa processos cognitivos e metacognitivos dos alunos (Pinto e Santos, 2006a).

Dessa forma, destaca-se a função reguladora da avaliação formativa no processo de ensino e de aprendizagem (Black e Wiliam, 1998b; Gardner, 2006; Fernandes, 2006; Santos, 2008, 2011) que intervém na melhoria dos processos de interação pedagógica e da comunicação que se estabelece em sala de aula, com vista à melhoria das aprendizagens dos alunos. É essa vertente reguladora que contribui para as aprendizagens dos alunos e que reclama práticas avaliativas que envolvam o questionamento, a escrita avaliativa, a negociação de critérios, o feedback, a autoavaliação e a coavaliação (Santos et al., 2010). Estes constituem os principais procedimentos de práticas de avaliação formativa que permitem a regulação dos processos de interação pedagógica e de comunicação que se estabelece entre os intervenientes da ação em sala de aula (Dias e Santos, 2010). 
A avaliação formadora e reguladora realizada em sala de aula não diz respeito, apenas, ao uso alternativo de determinados instrumentos de avaliação, como salientam Gipps e Stobart (2003, p. 550): "Não é simplesmente a utilização de formas de avaliação alternativa, mas é também uma utilização alternativa da avaliação como parte do ensino e da aprendizagem". Para que a avaliação seja efetivamente formadora e reguladora e contributiva para a aprendizagem dos alunos, deve ter em consideração as particularidades de cada um, respeitando a sua forma de pensar e de aprender, na medida em que o mesmo feedback pode ser útil para um aluno e não ser útil para outro (Bruno, 2006; Dias e Santos, 2009; Santos e Dias, 2006; Santos, 2011). No entanto, esse procedimento requer que sejam elaborados critérios de avaliação específicos para as tarefas realizadas, de acordo com as características de cada aluno. Ao contrário da avaliação sumativa, a avaliação formativa com função reguladora tem como principal objetivo ajudar a aprendizagem dos alunos (Santos, 2011), tendo em conta a sua individualidade.

Nesse contexto, é importante que sejam os alunos os protagonistas da sua avaliação, por meio do conhecimento de todos os critérios relativamente às tarefas propostas, sendo privilegiada a autoavaliação regulada das suas aprendizagens, encarada como um processo de metacognição e, como tal, um meio de aprendizagem (Santos, 2002). Esse processo tem caráter interativo e contínuo e potencia a participação dos alunos por intermédio de processos de autoavaliação, autorregulação e autocontrolo decorrentes do feedback (Fernandes, 2005, 2006, 2007; Hadji, 1992a, 1992b, 2001; Santos, 2002, 2008). Dessa forma, nesta aceção a modalidade de avaliação explanada traduz-se numa reunião entre as perspetivas francófonas e anglo-saxónicas: centra o aluno na sua própria acção, por meio da autorregulação dos processos de aprendizagem. O feedback fornecido pelo professor e a autoavaliação têm aqui especial destaque, uma vez que permitem que a autorregulação possa acontecer, no sentido de tomar decisões para a melhoria das aprendizagens (Fernandes, 2007).

\section{PRÁTICAS E PERCEÇÕES SOBRE AVALIAÇÃO}

As práticas e perceções dos professores e alunos sobre avaliação das aprendizagens têm sido alvo de alguns estudos, como os de Barreira e Pinto (2005), Cid, Cristóvão e Salgueiro (2013), Fernandes (2006), Fernandes (2008a, 2008b), Hoffman (2005), Luckesi (2013), Pinto e Santos (2006a, 2006b), Rosário, Araújo e Fialho (2012), Santiago et al. (2012), Santos e Pinto (2003) e Silva e Lucena (2015), no âmbito das mais diversas áreas curriculares. Esses estudos defendem que, em geral, os professores têm falta de conhecimentos na área da avaliação, e em particular da formativa, uma vez que o processo avaliativo que se efetua nas escolas passa, na sua maioria das vezes, pela classificação e seleção de alunos, e não tanto por um processo formativo que garanta o desenvolvimento das aprendizagens. Por essa razão, os professores devem investir na aprendizagem da avaliação, de modo a promover processos formativos que impliquem a fácil aquisição e controle de aprendizagens dos alunos (Luckesi, 2013). 
No entanto, Barreira e Pinto (2005), Fernandes (2006) e Rosário, Araújo e Fialho (2012), baseados em estudos sobre as perceções dos professores acerca da avaliação formativa, referem que muitos professores percecionam a avaliação formativa como um meio que permite a regulação das aprendizagens e dos processos que lhe estão inerentes, apesar de, em alguns casos, as suas práticas avaliativas se revelarem dissonantes das suas perceções e dos normativos legais que se encontram em vigor, tal como já foi referido (Santiago et al., 2012). Muito embora associada a essa realidade, ainda se pode observar a influência do paradigma psicométrico,já que muitos professores revelam preferir práticas tradicionais de avaliação, como a aplicação de testes de avaliação sumativa (Fernandes, 2008a; Santiago et al., 2012). $\mathrm{Na}$ verdade, muitos professores revelam dificuldades em alterar as suas práticas avaliativas, por isso a avaliação não passou a ser predominantemente formativa, nem os testes de avaliação deixaram de existir no sistema de avaliação (Fernandes, 2006; Rosário, Araújo e Fialho, 2012; Santiago et al., 2012), apesar de se realizarem trabalhos de grupo, apresentações orais, fichas de trabalho e produção de textos (Barreira e Pinto, 2005). Os testes de avaliação continuam, hoje, ainda, a ser o principal instrumento de avaliação das aprendizagens, por serem considerados por muitos docentes o instrumento que melhor permite quantificar os conhecimentos dos alunos, muito embora sejam concetualmente inadequados para responder aos objetivos dos atuais currículos (Fernandes, 2006; Rosário, Araújo e Fialho, 2012; Santiago et al., 2012).

\section{METODOLOGIA}

Em termos de opções metodológicas, a especificidade do objeto e os objetivos da investigação justificaram o estudo de caso instrumental como a estratégia metodológica mais adequada a desenvolver. $\mathrm{O}$ design de investigação seguiu uma orientação procedimental que nos permitiu estabelecer inferências a partir da análise dos dados e das respetivas conclusões, sendo depois estabelecidas algumas extrapolações.

Dada a natureza do problema, a investigação assentou num paradigma de investigação interpretativo, recorrendo a dados qualitativos provenientes de instrumentos e técnicas de recolha de dados que incluíram a entrevista individual (professor titular das turmas), a entrevista em focus group (alunos de duas turmas na disciplina de Ciências Naturais e de Biologia e Geologia) e a observação de aulas. A análise de conteúdo foi a ferramenta usada para a compreensão dos significados produzidos pelos participantes ouvidos em entrevista.

\section{RESULTADOS}

As estratégias de ensino e os instrumentos de aprendizagem implementados, nos contextos do estudo desenvolvido, foram sobretudo direcionados para a explanação de conteúdos e a consolidação de conhecimentos, o que coloca as estratégias implementadas nas salas de aula referentes ao $7 .^{\circ}$ ano e $11 .^{\circ}$ ano de escolaridade numa aceção mais tradicional do ensino, embora fazendo uso de instrumentos e ferramentas de aprendizagem diversificados. Todavia, as estratégias de ensino 
selecionadas estão longe de considerar o aluno como assumindo o papel central no processo de ensino, de avaliação e de aprendizagem, muito embora as atuais correntes de pensamento nos encaminhem nesse sentido. Consequentemente, pela mesma linha de pensamento, as estratégias de avaliação seguidas também se encontram pouco integradas nos processos de ensino e de aprendizagem, existindo mesmo um distanciamento entre eles, pois a avaliação é vista como um acontecimento formal que ocorre em cada período letivo, encontrando-se desligada dos processos formativos que a aprendizagem deve comportar.

Relativamente às perceções sobre a avaliação do professor e dos alunos das turmas em estudo, elas são semelhantes, conforme ilustra o Quadro 1.

Quadro 1. Análise de conteúdo da entrevista ao professor e aos alunos (focus group).

\begin{tabular}{|c|c|c|c|c|}
\hline Tema & Categoria & Subcategoria & $\begin{array}{c}\text { Indicadores - } \\
\text { Professor }\end{array}$ & $\begin{array}{c}\text { Indicadores - } \\
\text { Alunos }\end{array}$ \\
\hline \multirow{3}{*}{ 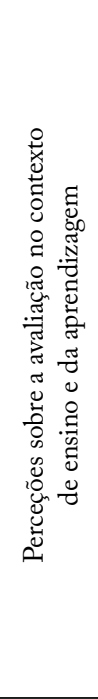 } & \multirow{3}{*}{$\begin{array}{l}\text { A- Perceções } \\
\text { sobre } \\
\text { avaliação } \\
\text { e sua } \\
\text { integração no } \\
\text { ensino e na } \\
\text { aprendizagem }\end{array}$} & $\begin{array}{l}\text { 1- Perceções sobre } \\
\text { avaliação }\end{array}$ & $\begin{array}{l}\text { a) Avaliação } \\
\text { predominantemente } \\
\text { sumativa. } \\
\text { b) Avaliação praticada } \\
\text { em sala de aula como } \\
\text { contributo para as } \\
\text { aprendizagens dos alunos. }\end{array}$ & $\begin{array}{l}\text { a) Sugestão de avaliação } \\
\text { alternativa. } \\
\text { b) Avaliação sumativa } \\
\text { como contributo para as } \\
\text { aprendizagens. }\end{array}$ \\
\hline & & $\begin{array}{l}\text { 2- Perceções } \\
\text { sobre a relação - } \\
\text { ensino, avaliação e } \\
\text { aprendizagem }\end{array}$ & $\begin{array}{l}\text { a) Processo de ensino, } \\
\text { avaliação e aprendizagem } \\
\text { centrado no professor. } \\
\text { b) Processo de ensino, } \\
\text { avaliação e aprendizagem } \\
\text { dependente da } \\
\text { intervenção dos alunos. }\end{array}$ & $\begin{array}{l}\text { a) Processo de ensino, } \\
\text { avaliação e aprendizagem } \\
\text { centrado no professor. }\end{array}$ \\
\hline & & $\begin{array}{l}\text { 3- Perceções sobre } \\
\text { o papel dos alunos } \\
\text { e do professor } \\
\text { no processo de } \\
\text { avaliação }\end{array}$ & $\begin{array}{l}\text { a) Alunos disponíveis para } \\
\text { aprender. } \\
\text { b) Professores atentos às } \\
\text { dificuldades dos alunos. }\end{array}$ & $\begin{array}{l}\text { a) Cabe ao professor ensinar } \\
\text { e avaliar e aos alunos } \\
\text { aprender. }\end{array}$ \\
\hline 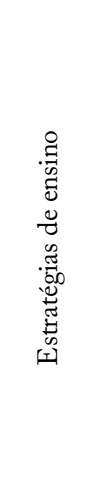 & $\begin{array}{l}\text { B-Dinâmicas } \\
\text { de sala de } \\
\text { aula }\end{array}$ & $\begin{array}{l}\text { 1- Atividades, } \\
\text { modalidades de } \\
\text { trabalho e recursos } \\
\text { didáticos utilizados } \\
\text { em sala de aula }\end{array}$ & $\begin{array}{l}\text { a) Atividades: exercícios } \\
\text { do manual escolar, fichas } \\
\text { de trabalho, atividades } \\
\text { laboratoriais e atividades } \\
\text { lúdicas. } \\
\text { b) Modalidades de } \\
\text { trabalho: trabalho } \\
\text { individual e por pares. } \\
\text { c) Recursos didáticos: } \\
\text { manual escolar, } \\
\text { apresentaçôes em } \\
\text { powerpoint, vídeos e } \\
\text { acetatos. }\end{array}$ & $\begin{array}{l}\text { a) Atividades: questões-aula, } \\
\text { atividades laboratoriais, } \\
\text { exercícios do manual escolar, } \\
\text { fichas de trabalho, análise de } \\
\text { imagens e questionamento } \\
\text { oral. } \\
\text { b) Modalidade de trabalho: } \\
\text { trabalho em grupo, por pares e } \\
\text { individual. } \\
\text { c) Recursos didáticos: } \\
\text { audiovisuais como apresentações } \\
\text { em powerpoint, transparências, } \\
\text { manual escolar, fichas de } \\
\text { trabalho e jogos. }\end{array}$ \\
\hline
\end{tabular}

Continua... 
Quadro 1. Continuação.

\begin{tabular}{|c|c|c|c|c|}
\hline Tema & Categoria & Subcategoria & $\begin{array}{c}\text { Indicadores - } \\
\text { Professor }\end{array}$ & $\begin{array}{c}\text { Indicadores - } \\
\text { Alunos }\end{array}$ \\
\hline 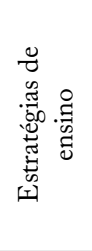 & $\begin{array}{l}\text { B-Dinâmicas } \\
\text { de sala de } \\
\text { aula }\end{array}$ & $\begin{array}{l}\text { 2- Atividades } \\
\text { que promovem } \\
\text { a participação, } \\
\text { autonomia e a } \\
\text { aprendizagem dos } \\
\text { alunos }\end{array}$ & $\begin{array}{l}\text { a) Participação: correção } \\
\text { oral de exercícios, } \\
\text { apresentação de trabalhos } \\
\text { e revisões de conteúdos } \\
\text { anteriores. } \\
\text { b) Autonomia: trabalhos } \\
\text { práticos e laboratoriais. }\end{array}$ & $\begin{array}{l}\text { a) Participação: correção oral } \\
\text { de exercícios. } \\
\text { b) Autonomia: atividades } \\
\text { práticas laboratoriais, } \\
\text { trabalhos de grupo, questões- } \\
\text { aula, fichas de trabalho e } \\
\text { exercícios do manual escolar. }\end{array}$ \\
\hline \multirow{6}{*}{ 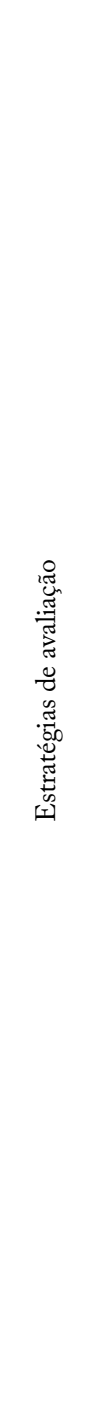 } & $\begin{array}{l}\text { C-Planificação } \\
\text { da avaliação }\end{array}$ & $\begin{array}{l}\text { 1- Planificação } \\
\text { dos momentos de } \\
\text { avaliação }\end{array}$ & $\begin{array}{l}\text { a) Avaliação prevista para } \\
\text { momentos formais. }\end{array}$ & $\begin{array}{l}\text { a) Avaliação efetuada em } \\
\text { momentos formais e no final } \\
\text { de cada período. }\end{array}$ \\
\hline & \multirow{5}{*}{$\begin{array}{l}\text { D- Avaliação } \\
\text { efetuada a } \\
\text { partir dos } \\
\text { diferentes } \\
\text { instrumentos } \\
\text { de avaliação }\end{array}$} & $\begin{array}{l}\text { 1- Instrumentos de } \\
\text { caráter sumativo }\end{array}$ & $\begin{array}{l}\text { a) Fichas de avaliação } \\
\text { sumativa. } \\
\text { b) Testes intermédios, no } \\
11 .^{\circ} \text { ano. }\end{array}$ & $\begin{array}{l}\text { a) Fichas de avaliação } \\
\text { sumativa. }\end{array}$ \\
\hline & & $\begin{array}{l}\text { 2- Instrumentos de } \\
\text { caráter formativo }\end{array}$ & $\begin{array}{l}\text { a) Fichas formativas, } \\
\text { questões-aula e exercícios } \\
\text { do manual escolar. }\end{array}$ & $\begin{array}{l}\text { a) Fichas formativas, } \\
\text { trabalhos de grupo, trabalhos } \\
\text { de casa, exercícios do } \\
\text { manual, questões-aula e } \\
\text { atividades laboratoriais. }\end{array}$ \\
\hline & & $\begin{array}{l}\text { 3- Avaliação } \\
\text { efetuada a partir } \\
\text { de instrumentos de } \\
\text { avaliação formativa }\end{array}$ & $\begin{array}{l}\text { a) Trabalhos de grupo e } \\
\text { relatórios experimentais. } \\
\text { b) Metodologia de } \\
\text { avaliação formativa é do } \\
\text { conhecimento dos alunos. } \\
\text { c) Resultados da avaliação } \\
\text { formativa integrados na } \\
\text { grelha de avaliação. }\end{array}$ & $\begin{array}{l}\text { a) Avaliação formativa } \\
\text { confinada a questões-aula, } \\
\text { relatórios e trabalhos de } \\
\text { grupo. }\end{array}$ \\
\hline & & $\begin{array}{l}\text { 4- Utilização } \\
\text { dos resultados da } \\
\text { avaliação para regular } \\
\text { as práticas de ensino }\end{array}$ & $\begin{array}{l}\text { a) Práticas de ensino } \\
\text { adaptadas de acordo com } \\
\text { os resultados da avaliação } \\
\text { dos alunos. }\end{array}$ & \\
\hline & & $\begin{array}{l}\text { 5- Critérios de } \\
\text { avaliação }\end{array}$ & $\begin{array}{l}\text { a) Critérios de avaliação } \\
\text { enquadrados na legislação. }\end{array}$ & $\begin{array}{l}\text { a) Critérios de avaliação } \\
\text { conhecidos e compreendidos } \\
\text { pelos alunos. } \\
\text { b) Critérios de avaliação } \\
\text { aplicados através de fichas } \\
\text { de avaliação, fichas de } \\
\text { trabalho, trabalhos de grupo, } \\
\text { participação, empenho e } \\
\text { atitudes e valores. } \\
\text { c) Critérios de avaliação } \\
\text { importantes na avaliação. } \\
\text { d) Atribuição da classificação } \\
\text { na área atitudes e valores } \\
\text { desconhecida pelos alunos. }\end{array}$ \\
\hline
\end{tabular}


Quadro 1. Continuação.

\begin{tabular}{|c|c|c|c|c|}
\hline Tema & Categoria & Subcategoria & $\begin{array}{c}\text { Indicadores - } \\
\text { Professor }\end{array}$ & $\begin{array}{c}\text { Indicadores - } \\
\text { Alunos }\end{array}$ \\
\hline \multirow{8}{*}{ 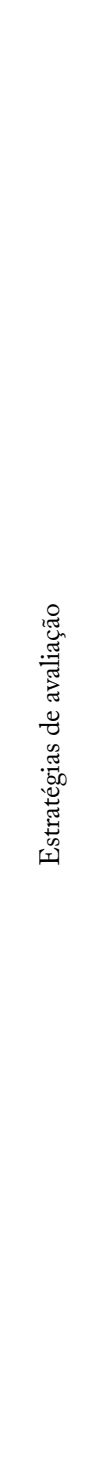 } & \multirow[b]{2}{*}{ E- Feedback } & $\begin{array}{l}\text { 1- Feedback } \\
\text { oral associado } \\
\text { aos diferentes } \\
\text { instrumentos de } \\
\text { avaliação }\end{array}$ & $\begin{array}{l}\text { a) Feedback oral associado } \\
\text { à correção das fichas de } \\
\text { avaliação sumativa. }\end{array}$ & $\begin{array}{l}\text { a) Feedback oral associado à } \\
\text { correção oral das fichas de } \\
\text { trabalho/formativas. }\end{array}$ \\
\hline & & $\begin{array}{l}\text { 2- Feedback } \\
\text { escrito associado } \\
\text { aos diferentes } \\
\text { instrumentos de } \\
\text { avaliação }\end{array}$ & $\begin{array}{l}\text { b) Feedback escrito } \\
\text { associado a chamadas } \\
\text { de atenção ou à correção } \\
\text { do erro, nas fichas de } \\
\text { avaliação sumativa e nos } \\
\text { relatórios experimentais. }\end{array}$ & a) Feedback escrito pouco útil. \\
\hline & $\begin{array}{l}\text { F-Participação } \\
\text { dos alunos na } \\
\text { avaliação }\end{array}$ & $\begin{array}{l}\text { 1- Envolvimento } \\
\text { dos alunos na } \\
\text { avaliação }\end{array}$ & $\begin{array}{l}\text { a) Participação dos alunos } \\
\text { na autoavaliação no final } \\
\text { do período e no final do } \\
\text { ano letivo. }\end{array}$ & $\begin{array}{l}\text { a) Participação dos alunos } \\
\text { na autoavaliação no final do } \\
\text { período e no final do ano } \\
\text { letivo. }\end{array}$ \\
\hline & \multirow{3}{*}{$\begin{array}{l}\text { G-Dinâmicas } \\
\text { de avaliação }\end{array}$} & $\begin{array}{l}\text { 1- Avaliação } \\
\text { diagnóstica }\end{array}$ & $\begin{array}{l}\text { a) Avaliação diagnóstica } \\
\text { escrita e oral. }\end{array}$ & $\begin{array}{l}\text { a) Avaliação diagnóstica, } \\
\text { escrita e oral. }\end{array}$ \\
\hline & & $\begin{array}{l}\text { 2- Autoavaliação e } \\
\text { heteroavaliação }\end{array}$ & $\begin{array}{l}\text { a) Auto e heteroavaliação } \\
\text { efetuada oralmente no } \\
\text { final de cada período. }\end{array}$ & $\begin{array}{l}\text { a) Autoavaliação efetuada no } \\
\text { final do período. } \\
\text { b) Heteroavaliação não aplicada }\end{array}$ \\
\hline & & $\begin{array}{l}\text { 3- Frequência da } \\
\text { avaliação formativa }\end{array}$ & $\begin{array}{l}\text { a) Avaliação formativa } \\
\text { frequente através de fichas } \\
\text { formativas, trabalhos de } \\
\text { grupo e questões orais. }\end{array}$ & \\
\hline & \multirow[t]{2}{*}{$\begin{array}{l}\text { H- } \\
\text { Importância } \\
\text { da avaliação } \\
\text { sumativa e } \\
\text { formativa e } \\
\text { sua } \\
\text { articulação }\end{array}$} & $\begin{array}{l}\text { 1- Avaliação } \\
\text { sumativa e } \\
\text { avaliação formativa }\end{array}$ & $\begin{array}{l}\text { a) Avaliação sumativa } \\
\text { resultante do tratamento } \\
\text { de dados procedentes dos } \\
\text { vários instrumentos de } \\
\text { avaliação. } \\
\text { b) Avaliação formativa } \\
\text { como contributo para as } \\
\text { aprendizagens. } \\
\text { c) Ambas importantes. }\end{array}$ & $\begin{array}{l}\text { a) Avaliação sumativa como } \\
\text { sendo a soma das notas de } \\
\text { todas as fichas de avaliação } \\
\text { sumativa efetuadas ao longo } \\
\text { do ano letivo. } \\
\text { b) Avaliação formativa } \\
\text { como contributo para as } \\
\text { aprendizagens. } \\
\text { c) Avaliação sumativa e } \\
\text { formativa estão relacionadas } \\
\text { e ambas são importantes. }\end{array}$ \\
\hline & & $\begin{array}{l}\text { 2- Integração da } \\
\text { avaliação formativa } \\
\text { e da avaliação } \\
\text { sumativa }\end{array}$ & $\begin{array}{l}\text { a) Avaliação formativa } \\
\text { pouco integrada na } \\
\text { avaliação final. }\end{array}$ & \\
\hline
\end{tabular}

A ênfase é colocada essencialmente nos processos de avaliação sumativa, como a resolução de fichas de avaliação enquanto processo de aferição e controlo de aprendizagens, para que se possam atribuir e seriar níveis de classificação entre alunos (Fernandes, 2008a). Essas aceções vão ao encontro dos resultados de estudos 
similares implementados por Pinto e Santos (2006a, 2006b), que indicam que a atribuição da classificação depende essencialmente do resultado das fichas de avaliação, que, por sua vez, são o instrumento de avaliação mais utilizado por permitir, no dizer dos professores, medir com rigor as aprendizagens dos alunos. Outros estudos, referidos por Fernandes (2008a, 2008b), indicam que os professores estão convictos de que as fichas de avaliação aferem aprendizagens profundas, no entanto, a investigação indica o contrário: os docentes dificilmente medem competências de alto nível.

Assim, no contexto da presente investigação, as fichas de avaliação continuam a ser o principal instrumento de avaliação das aprendizagens, apesar de os normativos legais considerarem a importância da implementação de práticas de índole formativa no processo de ensino e de aprendizagem (Portugal, 2016).

Relativamente à avaliação implementada em sala de aula, neste caso predominantemente sumativa, ela é eficaz na opinião do professor e dos alunos, uma vez que os alunos são obrigados a estudar para melhorarem os resultados obtidos nas fichas de avaliação. No entanto, segundo autores como Santos (2003), a avaliação sumativa não está verdadeiramente ao serviço da aprendizagem, pois ela visa sobretudo satisfazer necessidades de ordem social, prestando contas sobre os resultados dos alunos aos encarregados de educação e ao sistema educativo.

Segundo o Despacho Normativo n. ${ }^{\circ}$ 30, de 19 de julho de 2001 (Portugal, 2001), a avaliação sumativa culmina numa síntese de informações acerca do desenvolvimento das aprendizagens e competências definidas no currículo, dando especial atenção à evolução do conjunto de aprendizagens, pelo que se infere que a avaliação não se encerra apenas na aquisição de conhecimentos (Leite e Fernandes, 2002). No entanto, depreendemos, por meio dos depoimentos e da análise dos critérios e das grelhas de avaliação, que a classificação dos alunos observados é obtida fundamentalmente por intermédio dos resultados da classificação alcançados nas fichas de avaliação sumativa, nas questões-aula, nos trabalhos de grupo e nos relatórios experimentais.

Para professor e alunos, o docente tem o papel mais importante no processo de ensino, avaliação e aprendizagem, cabendo a ele ensinar e avaliar, e aos alunos, aprender. Denota-se, assim, que a perceção sobre a relação ensino, avaliação e aprendizagem é redutora, tendo em conta que os depoimentos demonstraram que os processos se encerram em si mesmos, não havendo relação entre eles. Os alunos identificam-se como recetores e reprodutores de conhecimentos e não consideram ter papel participativo no seu processo de ensino, de avaliação e de aprendizagem. No entanto, o professor considera que a participação dos alunos por meio das suas intervenções pode ser uma mais-valia para a modificação das estratégias de ensino, mas as evidências indicam que as estratégias implementadas não sofreram qualquer alteração, tendo em conta as dúvidas e observações colocadas pelos alunos.

O professor mostra-se preocupado com a aprendizagem dos alunos, referindo que o papel do professor é estar atento às dificuldades dos alunos, de modo a atuar em conformidade, e parte do princípio de que os alunos devem estar motivados e predispostos para aprender, caso contrário não existirá aprendizagem. Na verdade, a motivação é considerada fator basilar no processo de ensino e de aprendizagem 
(Oliveira e Oliveira, 1999) e a vontade dos alunos para desenvolver determinadas tarefas ligadas a processos cognitivos, como a capacidade de concentração, de atenção, de processamento de informação, de raciocínio e resolução de problemas, depende da sua motivação e predisposição (Lourenço e Paiva, 2010; Neto, 2013). Um dos grandes problemas da motivação é, contudo, a dificuldade que os professores revelam no diagnóstico das necessidades dos seus alunos e da sua própria motivação para ensinar e se desenvolver profissionalmente (Ribeiro, 2011).

Em suma, relativamente às perceções sobre avaliação e à forma como ela integra o processo de ensino e de aprendizagem, podemos inferir dos resultados obtidos que as perceções do professor e dos alunos envolvidos no estudo enquadram-se sobretudo num quadro concetual de avaliação como medida, que configura a avaliação sumativa realizada em sala de aula, em momentos formais para o efeito, por meio de fichas de avaliação sumativa, cujos conteúdos se relacionam com os saberes exigidos nos programas.

O objetivo desse tipo de avaliação é o controlo do desempenho escolar dos alunos no final de cada unidade programática, por meio de juízos avaliativos e menções quantitativas que contribuam para a retenção ou a progressão do aluno. Nesse sistema, a aprendizagem é associada à assimilação e à reprodução de conteúdos em momentos formais de avaliação (Pinto e Santos, 2006b).

Os dados obtidos na nossa investigação revelam-nos que, para professor e alunos, a avaliação serve apenas para inferir conhecimentos sobre conteúdos lecionados e, a partir daí, agir em conformidade, instigando-os a estudar mais e a estarem mais atentos nas aulas.

É de salientar que o professor considera que a avaliação por ele praticada é benéfica para os alunos, uma vez que quando não obtêm resultados satisfatórios nas fichas de avaliação são obrigados a estudar e a verificar onde foi cometido o erro, tal como já foi referido. Mas dificilmente essa prática permite aos alunos melhorar as baixas expectativas e colmatar as suas fragilidades no processo de aprendizagem, uma vez que esse método não pressupõe um processo de regulação das aprendizagens por meio de mecanismos formativos, tais como a autorregulação e a autoavaliação das aprendizagens ou a utilização do feedback oral ou escrito, como instrumento de melhoria.

Tal como refere Luckesi (2013), se os resultados dos alunos não corresponderem ao que era esperado, o professor deve repensar as suas práticas, estar atento às dificuldades e às necessidades dos alunos e diversificar os instrumentos de avaliação, de modo que se sintam "satisfeitos". Como tal, a melhor forma de o professor aprender sobre avaliação é olhar para a sua prática (Luckesi, 2013).

As perceções sobre avaliação formativa, tal como os participantes do estudo a concebem, manifestam-se na realização de fichas de trabalho, exercícios, questionamento, trabalhos de casa, de grupo e laboratoriais. Essa perspetiva vem ao encontro do que Fernandes (2008a, 2008b) identificou como a tendência dos professores (que influenciam os seus alunos) em julgar que ao implementarem essas tarefas estão a desenvolver a avaliação formativa. No entanto, a investigação em sala de aula indica o contrário, mostrando que existe alguma confusão entre os conceitos de avaliação formativa e avaliação certificativa ou sumativa, com poucas práticas formativas propriamente ditas em sala de aula. 
Assim, a avaliação formativa é percecionada pelos nossos participantes apenas como uma forma de ajudar os alunos na consolidação de conhecimentos, por meio da aplicação de fichas, relatórios, trabalhos de grupo, e não como um processo que pode ajudar o aluno a regular o seu processo de aprendizagem, no sentido que os normativos também referem.

A aplicação das práticas de avaliação pelos professores depende das suas perceções e conceções, decorrentes da sua própria experiência avaliativa, que geralmente implica processos tradicionais de avaliação, como a aplicação de testes de avaliação em momentos formais e a prática de uma avaliação formativa singrada em pressupostos ainda behavioristas, tais como a implementação de estratégias de remediação e a realização de fichas formativas que anteveem a realização do teste de avaliação. Nesse contexto, é difícil erradicar hábitos avaliativos, o que dificulta a mudança de práticas avaliativas e, consequentemente, coloca obstáculos ao processo de ensino e de aprendizagem (Luckesi, 2013; Pinto e Santos, 2006b).

Embora as perceções e as práticas avaliativas dos professores se influenciem mutuamente, elas não mudam simplesmente, nem se estabelecem de forma linear (Pinto e Santos, 2006b). Dessa forma, cabe à escola estabelecer formas de desenvolvimento profissional que permitam ajudar os professores a implementar a avaliação formativa em sala de aula, passando por processos de partilha e de regulação das suas práticas (Pinto e Santos, 2006b; Rosário, Araújo e Fialho, 2012).

Assim, avaliar e aprender aparecem, nesse cenário, como que dimensões distintas nas práticas pedagógicas dos professores (Pinto e Santos, 2006a, 2006b; Santiago et al., 2012), embora exista forte tendência dos professores para pensar que implementam tarefas de índole formativa, em sala de aula, que permitem ajudar os alunos no seu processo de aprendizagem. Tal como refere Santiago et al. (2012), no âmbito da análise da Organização para a Cooperação e Desenvolvimento Econômico (OCDE), é notória a valorização da função classificativa ou certificativa da avaliação em Portugal, numa lógica de preparação para a avaliação externa, em detrimento de uma avaliação para a identificação de necessidades, que vise a melhoria do processo de aprendizagem (Fernandes, 2008a, 2008b; OCDE, 2005; Santiago et al., 2012).

A investigação indica que, de forma geral, os professores pensam, vivem e praticam a avaliação de forma isolada, o que explica a falta de confiança que eles revelam ter diante de suas avaliações, dos procedimentos e das decisões que daí decorrem (Fernandes, 2008a, 2008b; Santos, 2008). Para tal, Fernandes (2004, p. 23) refere que "uma 'política' de avaliação de escola, que integre as principais preocupações dos professores e que valorize as suas experiências e saberes, pode ser uma ideia com bom acolhimento". A integração da avaliação e de referenciais nos projetos educativos das escolas e a reflexão conjunta entre professores sobre essa problemática poderiam estar na base da mudança, com a definição de critérios de avaliação que permitissem implementar uma avaliação de cariz formativo, por meio da diversificação de estratégias, técnicas e instrumentos de avaliação, da integração de maior número de informação na avaliação, da atribuição de classificações, da identificação de funções de avaliação, do envolvimento dos alunos e das famílias, da frequência, da distribuição e da natureza do feedback ou das questões de validade, fiabilidade e de equidade (Fernandes, 2004). 


\section{CONCLUSÕES}

As práticas avaliativas implementadas, em ambos os anos de escolaridade em estudo, colocam a ênfase sobretudo na aquisição de aprendizagens que privilegiam a memorização de conteúdos e nas quais o método de ensino predominante é do tipo expositivo, com recurso a instrumentos de avaliação de caráter predominantemente sumativo. Pensamos que essas práticas avaliativas implementadas influenciam fortemente as perceções dos alunos sobre a avaliação das aprendizagens.

Avaliar e aprender aparecem, nesse cenário, como que dimensões distintas nas práticas pedagógicas do professor. No entanto, a avaliação não se pode encerrar apenas na verificação da aquisição de conhecimentos e na sua respetiva classificação e, como tal, torna-se necessária uma mudança de mentalidades e de práticas letivas. Nesse sentido, cabe às escolas a integração da avaliação como processo formador e regulador das aprendizagens nos projetos educativos e a disponibilização de formação nesse âmbito. Não obstante, a melhor forma de o professor aprender sobre avaliação é desenvolver a capacidade de observar e refletir sobre as suas próprias práticas.

Será de apostar, no entanto, numa formação docente que assente no desenvolvimento de professores reflexivos, de modo a serem capazes de transformar e melhorar as suas práticas pedagógicas. Assim, poderia ver-se reforçada a implementação de práticas de avaliação formativa, ou melhor, práticas de avaliação formadora e reguladora das aprendizagens, em que o aluno tenha papel central no processo e seja implementada a distribuição de feedback e a autoavaliação como estratégias de autorregulação das aprendizagens, de modo a dar oportunidade ao aluno de tomar decisões sobre o caminho a percorrer em direção aos objetivos delineados.

\section{REFERÊNCIAS}

ABRECHT, R. L'évaluation formative: une analyse critique. Bruxelles: De Boeck, 1991. ALLAL, L. Estratégias de avaliação formativa: conceções psicopedagógicas e modalidades de aplicação. In: ALLAL, L.; CARDINET, J.; Perrenoud, P. (org.). A avaliação formativa num ensino diferenciado. Coimbra: Almedina, 1986. p.175-209. ALLAL, L. Impliquer l'apprenant dans le processus d'évaluation: promesses et piéges de l'autoévaluation. In: Depover, C.; Nöel, B. (org.). L'évaluation des competences et des processus cognitifs: modéles, pratiques et contexts. Bruxelles: De Boeck Université, 1999. p. 35-56.

ALLAL, L. Régulations des apprentissages: orientations conceptuelles pour la recherché et la pratique en éducation. In: ALLAL, L.; MOTTIER LÓPEZ, L. Régulation des apprentissages en situation scolaire et en formation. Bruxelles: De Boeck Université, 2007.p. 7-23.

ALLAL, L. Assessment and the regulation of learning. In: PETERSON, E. B. P. (org.). International Encyclopedia of Education. Oxford: Elsevier, 2010. v. 3. p. 348-352. ANDRADE, H. Classroom assessment in the context of learning theory and research. In: MCMILLAN, J. H. (org.). Sage handbook of research on classroom assessment. Londres: Sage, 2013. p. 17-34. 
BARREIRA, C.; PINTO, J. A investigação em Portugal sobre a avaliação das aprendizagens dos alunos (1990-2005). 2005. Disponível em: http://www.educ.fc.ul. pt/docentes/msantos/spce.pdf. Acesso em: mar. 2014.

BERLAK, H. The need for a new science of assessment. In: BERLAK, H. et al. (org.). Toward a new science of educational testing and assessment. Albany: State University of New York Press, 1992a. p. 1-22.

BERLAK, H. Toward the development of a new science of educational testing and assessment. In: BERLAK, H. et al. (org.). Toward a new science of educational testing and assessment. Albany: State University of New York Press, 1992b. p. 181-206.

BLACK, P. Formative and summative aspects of assessment: theoretical and research foundations in the context of Pedagogy. In: MCMILLAN,J.H. (org.). Sage handbook of research on classroom assessment. London: Sage, 2013. p. 167-178.

BLACK, P. et al.Assessment of learning: Putting it into practice. Buckingham: Open University Press, 2011.

BLACK, P.; WILIAM, D. Assessment and classroom learning. Assessment in Education, v. 5, n. 1, p. 7-74, 1998a. https://doi.org/10.1080/0969595980050102

BLACK, P.; WILIAM, D. Inside the black box: Raising standards through classroom assessment. London: Department of Education \& Professional Studies, Kings College, 1998b.

BLACK, P.; WILIAM, D. Assessment for learning in the classroom. In: GARDNER, J. (org.). Assessment and learning. London: Sage, 2006a. p. 9-26

BLACK, P.; WILIAM, D. Developing a theory of formative assessment. In: GARDNER, J. (org.). Assessment and learning. London: Sage, 2006b. p. 81-100.

BONNIOL, J.; VIAL, M. Modelos de avaliação: textos fundamentais. Porto Alegre: Artmed, 2001.

BORRALHO, A.; FIALHO, I.; CID, M. A Triangulação sustentada de dados como condição fundamental para a investigação qualitativa. Revista Lusófona de Educação, v. 29, p. 53-69, 2015. Disponível em: http://revistas.ulusofona.pt/index.php/rleducacao/ article/view/5094/3307. Acesso em: maio 2015.

BRUNO, I. Avaliação das aprendizagens: o processo de regulação através do feedback: um estudo em físico-química no $3^{\circ}$ ciclo de ensino básico. Tese (Mestrado em Educação) - Universidade de Lisboa, Lisboa, 2006.

CARDINET, J. L'apport sociocognitif à la régulation interactive. In: WEISS, J. (org.). Lévaluation: Problème de Communication. Cousset (Fribourg): Delval, 1991. p. 199-213.

CID, M.; CRISTÓVÃO, A. M.; SALGUEIRO, H. Projeto TurmaMais: importância da formação em avaliação das aprendizagens. In: PEDAGOGIA 2013. Encuentro por la Unidad de los Educadores. Havana: Editor Educación Cubana, 2013.

CID, M.; FIALHO, I. Avaliar para aprender na escola: um caminho em aberto. In: FIALHO, I.; VERDASCA, J. (org.). TurmaMais e sucesso escolar: trajetórias para uma nova cultura de escola. Évora: Centro de Investigação em Educação e Psicologia, Universidade de Évora, 2013. p. 79-89. 
CRAHAY, M. Feedback de l'enseignant et apprentissages des élèves: revue critique de la literature de recherché. In: ALLAL, L.; MOTTIER LÓPEZ, L. (org.). Régulation des apprentissages en situation scolaire et en formation. Bruxelas: De Boeck Université, 2007. p. 45-70.

DIAS, S.; SANTOS, L. Avaliação reguladora, feedback escrito, conceitos matemáticos: um triângulo de difícil construção. In: SIEM, 20., 2009. Anais... Viana do Castelo: Associação de Professores de Matemática, 2009. CD-ROM.

DIAS, S.; SANTOS, L. O feedback e os diferentes tipos de tarefas matemáticas. In: SIEM, 20., 2010. Anais... Aveiro, 2010. p. 126-136.

DWYER, C. Assessment and classroom learning: theory and practice. Assessment in Education: Principles, Policy \& Practice, v. 5, n. 1, p. 131-137, 1998. https://doi. org/10.1080/0969595980050109

FERNANDES, D. Avaliação das aprendizagens: uma agenda, muitos desafios. Lisboa: Texto, 2004.

FERNANDES, D. Avaliação das aprendizagens: refletir, agir e transformar. In: Futuro Congressos e Eventos (org.). $3^{\circ}$ Congresso Internacional Sobre Avaliação na Educação. Curitiba: Futuro Eventos, 2005. p. 65-78.

FERNANDES, D. Para uma teoria da avaliação formativa. Revista Portuguesa de Educação, v. 19, n. 2, p. 21-50, 2006.

FERNANDES, D. Vinte e cinco anos de avaliação das aprendizagens: uma síntese interpretativa de livros publicados em Portugal. In: Estrela, A. (org.). Investigação em educação: teorias e práticas (1960-2005). Lisboa: Educa, 2007. p. 261-306.

FERNANDES, D. Avaliação das aprendizagens: desafios às teorias, práticas e políticas. Lisboa: Texto, 2008a.

FERNANDES, D. Para uma teoria da avaliação no domínio das aprendizagens. Estudos em Avaliação Educacional, v. 19, n. 41, p. 347-372, 2008 b.

FERNANDES, D. Avaliação das aprendizagens em Portugal. Investigação e teoria da atividade. Sisifo. Revista de Ciências da Educação, n. 9, p. 87-100, 2009a.

FERNANDES, D. Educational assessment in Portugal. Assessment in Education: Principles, Policy \& Practice, v. 16, n. 2, p. 227-247, 2009b. https://doi. org/10.1080/09695940903076055

FERREIRA, C. A. A avaliação no quotidiano da sala de aula. Porto: Porto, 2007.

FERREIRA, C. A. Avaliação das aprendizagens: entre a certificação e a regulação. Correio da Educação, 2010. Disponível em: http://correiodaeducacao.asa.pt/72863. html. Acesso em: maio 2015.

GARDNER, J. Assessment and learning. London: Sage, 2006.

GIPPS, C. Beyond testing: towards a theory of educational assessment. London: Falmer, 1994.

GIPPS, C. Sociocultural aspects of assessment. Review of Research in Education, v. 24, n. 1, p. 355-392, 1999. https://doi.org/10.3102\%2F0091732X024001355 
GIPPS, C.; STOBART, G. Alternative assessment. In: KELLAGHAN, T.; STUFFLEBEAM, D. (org.). International handbook of educational evaluation. Dordrecht: Kluwer, 2003. p. 549-576.

GRÉGOIRE, J. Évaluer des apprentissages: les apports de la psychologie cognitive. Bruxelas: De Boeck, 1996.

HADJI, C. Évaluation, règles du jeu. Paris: ESF, 1992a.

HADJI, C.L'évaluation des actionséducatives. Paris: Presses Universitaires de France, 1992b. HADJI, C. Avaliação desmistificada. Porto Alegre: Artmed, 2001.

HARLEN,W.On the relationship between assessment for formative and summative purposes. In: GARDNER, J. (org.). Assessment and learning. London: Sage, 2006. p. 103-118.

HARLEN, W.; JAMES, M. Assessment and learning: differences and relationships between formative and summative assessment. Assessment in Education: Principles, Policy and Practice, v. 4, n. 3, p. 365-379, 1997. https://doi. org/10.1080/0969594970040304

HOFFMANN, J. O jogo do contrário em avaliação. Porto Alegre: Mediação, 2005. JAMES, M. Assessment, teaching and theories of learning. In: GARDNER, J. (org.). Assessment and learning. London: Sage, 2006. p. 47-60.

LEITE, C.; FERNANDES, P. Avaliação das aprendizagens dos alunos: novos contextos, novas práticas. Porto: Asa, 2002.

LOURENÇO, A.; PAIVA, M. A motivação escolar e o processo de aprendizagem. Ciências \& Cognição, Rio de Janeiro, v. 15, n. 2, p. 132-141, 2010. Disponível em: http://www.cienciasecognicao.org/revista/index.php/cec/article/view/313/195. Acesso em: mar. 2015.

LUCKESI, C. Avaliação da aprendizagem escolar: estudos e preposições. São Paulo: Cortez, 2013.

NETO, A. J. Para uma didática das ciências transdisciplinar: o contributo da aprendizagem baseada na resolução de problemas. In: ENCONTRO SOBRE EDUCAÇÃO EM CIÊNCIAS ATRAVÉS DA APRENDIZAGEM BASEADA NA RESOLUÇÃO DE PROBLEMAS, 2013, Braga. Atas... Braga: CIEd, Universidade do Minho, 2013.

NUNZIATI, G. Pour construire un dispositif d'évaluation formatrice. Cahiers Pédagogiques, n. 280, p. 47-64, 1990.

OLIVEIRA, J. H. B.; OLIVEIRA, A. M. B. Psicologia da educação escolar: alunoaprendizagem. Coimbra: Almedina, 1999.

ORGANISATION FOR ECONOMIC CO-OPERATION AND DEVELOPMENT (OCDE). Formative Assessment: Improving Learning in Secondary Classrooms. Policy Brief, nov. 2005. Disponível em: https://www.oecd.org/ edu/ceri/35661078.pdf. Acesso em: jun. 2015.

PACHECO, J. Critérios de avaliação na escola. In: ABRANTES, P.; ARAÚJO, F. (org.). Reorganização curricular do ensino básico: avaliação das aprendizagens. Das conceções às práticas. Lisboa: Ministério da Educação,Departamento da Educação Básica, 2002. p. 55-64. 
PARÍS, E. La regulación en la fase de desarollo de la secuencia formativa. In: BÉLTRAN, M. et al. La secuencia formativa: fases de desarollo y de sínteses. Barcelona: Editorial Graó, 2006. p. 15-24.

PERRENOUD, P.Avaliação: da excelência à regulação das aprendizagens. Entre duas lógicas. Porto Alegre: Artmed, 1999.

PINTO, J.; SANTOS, L.É mesmo possível uma regulação no quotidiano do trabalho do professor e do aluno? In: ProfMat 2006. Lisboa: APM, 2006a. CD-ROM.

PINTO, J.; SANTOS, L. Modelos de avaliação das aprendizagens. Lisboa: Universidade Aberta, 2006b.

PORTUGAL. Despacho normativo n. ${ }^{\circ}$ 30, de 19 de junho de 2001. Portugal, 2001. PORTUGAL. Despacho normativo n. ${ }^{\circ}$ 1-F/2016. Portugal, 2016.

RIBEIRO, F. Motivação e aprendizagem em contexto escolar. PROFFORMA, nº 03, 2011. Disponível em: http://cefopna.edu.pt/revista/revista_03.htm. Acesso em:jul.2015. ROSÁRIO, F.; ARAÚJO, L.; FIALHO, I. Avaliação formativa e formação de professores. In: ENCONTRO REGIONAL DE EDUCAÇÃO - APRENDER NO ALENTEJO, 7., 2012. Atas... Évora: Universidade de Évora, 2012.

SADLER, D. Formative assessment and the design of instructional systems. Instructional Science, v. 18, n.2, p. 119-144, 1989.

SANTIAGO, P. et al. OECD Reviews of Evaluation and Assessment in Education: Portugal 2012. OECD Publishing, 2012. Disponível em: http://dx.doi. org/10.1787/9789264117020-en. Acesso em: jun. 2015.

SANTOS, L. Autoavaliação regulada: porquê, o quê e como? In: ABRANTES, P.; ARAÚJO, F. (org.). Avaliação das aprendizagens: das conceções às práticas. Lisboa: DEB, 2002. p. 75-84.

SANTOS,L.A investigação em Portugal na área da avaliação pedagógica em Matemática. In: SEMINÁRIO DE INVESTIGAÇÃO EM EDUCAÇÃO MATEMÁTICA, 14., 2003. Atas. Lisboa: Associação de Professores de Matemática, 2003. p. 9-27.

SANTOS, L. Dilemas e desafios da avaliação reguladora. In: MENEZES, L. et al. (org.). Avaliação em matemática: problemas e desafios. Viseu: Secção de Educação Matemática da Sociedade Portuguesa de Ciências de Educação, 2008. p. 11-35.

SANTOS, L. Que critérios de qualidade para a avaliação formativa? In: FERNANDES, D. (org.). Avaliação em educação: olhares sobre uma prática social incontornável. Curitiba: Melo, 2011. p. 155-165.

SANTOS, L.; DIAS, S. Como entendem os alunos o que lhes dizem os professores? A complexidade do feedback. In: PROFMAT, 2006. Anais... Lisboa: APM, 2006. CD-ROM.

SANTOS, L.; PINTO, J. O que pensam os alunos sobre avaliação? Educação e Matemática, v. 74, 2003.

SANTOS, L. et al. (org.). Avaliar para aprender: relatos de experiências de sala de aula do pré-escolar ao ensino secundário. Porto: Porto, 2010. 
SHEPARD, L. The role of assessment in a learning culture. Educational Researcher, v. 29, n. 7, p. 4-14, 2000. https://doi.org/10.3102\%2F0013189X029007004

SHEPARD, L. The role of classroom assessment in teaching and learning. In: RICHARDSON, V. (org.). Handbook of Research on Teaching. 4. ed. Nova York: MacMillan, 2001. p. 1066-1101.

SILVA, B.; LUCENA,I.Perceções de alunos sobre avaliação e autoavaliação no contexto escolar. In: CONGRESSO NACIONAL SOBRE EDUCAÇÃO, 2., 2015, Campina Grande. Anais... 2015.

STIGGINS, R. New assessment beliefs for a new school mission. Phi Delta Kappa, v. 86, n. 1, p. 22-27, 2004. https://doi.org/10.1177\%2F003172170408600106

STIGGINS, R.; CONKLIN, N. In teachers' hands: investigating the practices of classroom assessment. Albany: State University of New York Press, 1992.

TRINDADE, R.; COSME, A. Educar e aprender na escola: questões, desafios e respostas pedagógicas. Vila Nova de Gaia: Fundação Manuel Leão, 2010.

WILIAM, D. Assessment for learning: why, what and how? London: Institute of Education, University of London, 2009.

\section{SOBRE AS AUTORAS}

Sónia de Jesus Elias Correia é doutora em ciências de educação pela Universidade de Évora (Portugal). Colaboradora da mesma instituição. E-mail: correiajesonia@gmail.com

Marília Pisco Castro Cid é doutora em ciências da educação pela Universidade de Évora (Portugal). Professora da mesma instituição. E-mail:mariliacid@gmail.com

Conflitos de interesse: Os autores declaram que não possuem nenhum interesse comercial ou associativo que represente conflito de interesses em relação ao manuscrito.

Financiamento: $\mathrm{O}$ estudo não recebeu financiamento.

Contribuições dos autores: Correia, S.J.E.: Investigação. Cid, M.P.C.: Supervisão.

Recebido em 15 de novembro de 2019 Aprovado em 9 de julho de 2020 